\title{
Should Parents Design Their Children's Genome: Some General Arguments and a Confucian Solution
}

\author{
Jianhui Li ${ }^{1,2, * \mathbb{D}}$ and Xin Zhang ${ }^{1}$ \\ 1 School of Philosophy, Beijing Normal University, Beijing 100875, China \\ 2 Beijing Normal University-Hong Kong Baptist University United International College, Zhuhai 519087, China \\ * Correspondence: ljh@bnu.edu.cn
}

Received: 19 May 2019; Accepted: 23 July 2019; Published: 30 July 2019

\begin{abstract}
With the emergence of clustered, regularly interspaced, short palindromic repeats (CRISPR)/CRISPR-associated protein 9 (Cas9) as one of the most promising new gene-editing techniques, scientists are now endeavoring to apply it to various domains. Among all the possible applications, gene editing in human embryos has received the most attention. Against this background, this article carries out a philosophical study on the ethical problems of human embryo gene editing or designing. Arguments against human embryo gene designing include that parents should be prohibited from deciding their children's future; commodifying children should be prohibited; the natural reproductive process should not be disturbed; and human embryo gene designing might foster discrimination. Arguments for human embryo gene designing include that parents should have the freedom to design their own babies and this freedom should not be limited; designing babies can promote the happy life of the baby; and totally forbidding embryo gene editing would drive the practice underground, where it would be performed illegally. This article analyzes all of these arguments and points out that all of them have some flaws. In order to draw a thoughtful conclusion, we turn to Confucianism and find a new perspective to determine whether designing babies with CRISPR technology is ethically permissible.
\end{abstract}

Keywords: CRISPR; genetic enhancement; embryonic genetic designing; bioethics; Confucianism

\section{Introduction}

Clustered, regularly interspaced, short palindromic repeats (CRISPR) is a biological system for altering DNA. It is a recently developed type of gene-editing technology that contains two central parts: CRISPR and CRISPR-associated (Cas) genes. A rough sketch of how CRISPR technology works goes as follows: CRISPR is a DNA sequence family that widely exists among genomes of bacteria and archaea. Each member of this family is composed of one leader, several short and conservative repeats, and several spacers. In particular, spacers are, most of the time, DNA sequences from invaders of bacteria and archaea. These exogenous sequences could help bacteria and archaea recognize the corresponding invaders when they invade again, and together with Cas genes, they could edit the genes of these invaders to inhibit their expression. Utilizing this mechanism, scientists can now edit many genes simply by producing the right kind of CRISPR-derived RNA (crRNA), combining it with Cas protein 9 (Cas9), letting the crRNA guide the complex to target genes, and then performing the editing work. This is how CRISPR technology works in general.

CRISPR technology is a revolutionary achievement in biology that is comparable to polymerase chain reaction (PCR) technology. Before the advent of CRISPR technology, although biologists were already capable of editing genes, the technologies they adopted (e.g., HEase, ZFN, and TALEA) were extremely complex and expensive. In contrast, CRISPR technology is both simple and inexpensive, which has been the key to its immediate popularity among biologists worldwide. Moreover, CRISPR 
technology has a wide range of potential applications, such as genetic disease treatment, transgenic technology, and even protective interventions for ecological systems. In short, CRISPR technology is turning many mere ideas into reality and, in turn, promises to significantly push forward the development of the life sciences. However, despite all the potential good that CRISPR technology promises to bring about, some still worry about its consequences. What will happen if the great power of this technology gets misused and elicits unforeseeable risks, or even disaster? Therefore, we are currently seeing a heated ethical debate over CRISPR technology and, in particular, its potential applications.

The chief worry over CRISPR's application nowadays is mainly about its safety. For instance, some people often worry about the off-target effects of CRISPR technology in its medical applications-that is, will the technology faithfully follow our will to only edit the target genes and work effectively? There is also the worry that CRISPR technology might fall into the hands of terrorists who would use it to create into deadly weapons. All of these worries over safety issues and the discussions around them are very reasonable and beneficial but, in this paper, we take a step further and focus on the following question: If the safety issues can be resolved, is it ethically permissible to apply this technology to embryo gene designing (EGD)?

EGD consists of parents adopting gene-editing technologies, such as CRISPR, to design their children's phenotypes. It is clear enough that before safety issues concerning CRISPR technology are resolved, EGD is off the table because that would inflict considerable risks not only onto the children themselves but also onto the offspring of these children, as edited genes can be transmitted across generations. Therefore, our discussion here is grounded on the premise that CRISPR technology is mature enough to warrant concerns over the safety of its application in EGD.

There is a tremendous amount of discussion in the current literature over EGD, a large portion of which holds that EGD will be forbidden anyway, even if the safety issues are resolved. Of course, there are also some arguments strongly supporting EGD. What are the core contents of these arguments? Are they strong enough to support a decisive denial or permission of EGD? We discuss these in Sections 2 and 3. After that, we rank the strengths of these arguments in Section 4 and then specifically focus on the Confucianist stance on this issue in Section 5. Therein, we suggest that, on the one hand, Confucianism answers questions left unanswered by current famous Western philosophers such as Sandel; on the other hand, Confucianism holds a more context-sensitive attitude towards EGD.

\section{Arguments against EGD and the Counterarguments}

Besides safety issues, there are many arguments against EGD. As we know, ideally, we should solve every bioethical problem by citing a deep ethical theory, especially one upon which all ethicists agree. However, as Engelhardt and many other ethicists have already suggested, it is hard for all people to uphold the same ethical theory [1]. For example, no fundamental theory, such as deontology, virtue theories, contract theories, pragmatism, utilitarianism, libertarianism, or religious theories, has been accepted by all ethicists. Thus, in bioethical practice, ethicists use moral principles as their practical solutions for solving specific ethical problems. Different people might propose different moral principles for solving concrete problems-for instance, Beauchamp and Childress proposed four bioethical principles, and Engelhardt gave several related but different principles to solve bioethical problems [1,2]. This strategy has been labeled by some as principlism. As we can see, different principles may come from different ethical theories, but practically, this works well in bioethics. In this paper, we follow this line of reasoning and find that in the debate over EGD, philosophers and bioethicists have proposed even more concrete bioethical principles to solve ethical problems. We try to cover all of these principles and check whether they are reasonable or not. We discuss these principles in the following sections. 


\subsection{Future Deciding Argument}

The future deciding argument asserts that EGD is morally wrong because, by carrying out this procedure, parents are deciding their children's futures, which is ethically problematic. As described earlier, EGD consists of parents designing their children's phenotype with the aid of gene-editing technologies such as CRISPR. Therefore, if the procedure is successfully performed, the children would exhibit the desired phenotype when they grow up. That is, the children would exhibit a certain phenotype completely due to their parents' will, and in this sense, parents have already decided their children's future and have thus compromised their autonomy.

Advocates of EGD reject the argument above. They contend that even without EGD, parents have been and are deciding their children's future without being susceptible to any moral blame. So, why should EGD alone be singled out for such scrutiny? For instance, parents in large part decide the education received by their children and it is agreed that education significantly affects one's future. So, should parents be held morally responsible for this? Apparently, no. The reason why we set a double standard for EGD is simply because it is unfamiliar, whereas education has existed for ages. But ethically, there is no difference between these two.

Opponents do not accept the counterargument above. They point out that advocates make an inappropriate analogy between EGD and education. For education, although parents do make a significant contribution to the decision-making process, children still have a say in it. That is, parents commonly ask their children about their preferences, and more importantly, children increasingly participate in the decision-making process as they grow older. For instance, in most cases, children dominate the decision-making process regarding the choice of college education. Besides, even if parents totally decide what education their children receive, this far from guarantees that their children would become their desired kind of person in the future. Therefore, in the case of education, parents are not overdeciding their children's future.

In contrast, in the case of EGD, parents are suspicious of overdeciding their children's future. Firstly, unlike the decision-making process regarding education, children have zero participation in the decision over EGD, while parents get the whole say. Secondly, unlike education, according to the ideal of EGD, once the genes are edited, the children are almost bound to take on the phenotype and there is hardly any way back. Therefore, compared to education, EGD is a case of parents overdeciding their children's future, and for this reason, it is inappropriate for advocates to put these two cases on the same level. Permission in the case of education does not warrant permission in the case of EGD.

But advocates of EGD would argue back as follows. Opponents categorize EGD as overdeciding the future while education does not, but is this the right categorization to accept? Advocates think otherwise. One of the reasons opponents regard EGD as overdeciding children's futures is that once genes are edited, children are bound to carry the desired phenotype. But current work in developmental biology falsifies this assertion. It is now acknowledged that non-DNA elements (epigenetic modifications, environment, and random factors) play a far more important role in phenotype development than had been assumed. Therefore, unlike what is suggested by opponents, children have a great chance to develop phenotypes other than the desired one set by EGD. Thus, it is difficult to determine why EGD should be categorized as overdeciding children's futures.

\subsection{Commodifying Argument}

The commodifying argument against EGD goes as follows: In essence, EGD consists of parents customizing perfect babies, and since customization commonly happens with commercial products, EGD is thus an activity of commodifying children and this is morally inappropriate [3].

Advocates are not convinced by the argument above, and their counterargument is quite similar to the one presented in Section 2.1. Advocates argue that there have been and are many other ways for parents to customize and commodify their children (e.g., education), which are largely deemed as ethically innocuous. So, why set a double standard for EGD? 
Opponents would argue back, like in Section 2.1, that advocates have made a wrong analogy here. Take education as an example. Although it is customizing children to a certain degree, it is apparently not overcustomizing because, firstly, sending a child to a particular kind of school does not guarantee he or she will become the parents' desired kind of person. Secondly, as mentioned in Section 2.1, children have an undeniable say in what kind of education they receive, and this say becomes increasingly decisive as they grow up. In contrast, EGD is overcustomizing children because, firstly, an ideal EGD would totally decide children's phenotypes and there is hardly any other alternative. Secondly, children's participation in the decision-making process is nonexistent.

Supporters, however, think otherwise. They express doubt about their opponents' categorization of EGD as overcustomizing. According to them, EGD does significantly influence children's phenotypes, but its influence is not nearly as decisive as assumed by opponents. As mentioned earlier, current developmental biology finds that non-DNA elements play an equally important role in phenotype formation as DNA. Consequently, after EGD, children still have a great chance to develop a phenotype other than the one desired by their parents. This motivates supporters to view EGD as not being a case of overcustomizing children.

\subsection{Playing God or Against Nature Argument}

The playing god or against nature argument holds that EGD should not be permitted because it is playing god or against nature. For instance, Kass holds that we should conform to nature and respect what is given to us by it [4]. Sandel argues that children are gifts for us, and we should not interfere with human nature [5]. Therefore, if EGD is indeed against nature in the sense that it disrespects what is given to us by nature, opponents do seem to have a case against EGD. But is this argument tenable? Advocates believe not.

Advocates argue that in many cases, being against nature is not ethically problematic, so we cannot forbid EGD on this basis. For example, senescence is part of nature because it is what nature has bestowed onto us and our ancestors. Then, following the logic of the against nature argument, all human activities combatting senescence are unethical because they represent disrespect to what nature gives to us. Shall we forbid all of these activities? No. So, how can we forbid EGD on the very same basis? In fact, the reason behind opponents' double standard for EGD is simply that activities against senescence have become norms while EGD has not become one. Therefore, it seems that the conforming to nature argument here is really not about EGD being against nature but about it being against norms. And this is apparently untenable, because something being against norms does not necessarily mean that it is ethically wrong.

\subsection{Prejudice Argument}

The prejudice argument contends that EGD should be forbidden because it encourages social prejudice against people without a perfect phenotype [5]. To illustrate, the phenotype that parents would have their children possess through EGD is generally taken to be a good phenotype (e.g., high IQ), while the phenotype that parents would avoid for their children through EGD is generally taken to be a bad phenotype. Therefore, by adopting EGD, parents are subscribing to existing prejudices against people exhibiting the so-called bad phenotype, and this is ethically wrong.

Supporters disagree with the prejudice argument because they think opponents are overexaggerating the situation. For instance, plastic surgery has now become a common procedure in many parts of the world, and like EGD, plastic surgery also has the risk of enhancing social prejudice against people not possessing so-called nice facial characteristics. But in fact, we do not see this prejudice being significantly enhanced today. On the contrary, society nowadays seems to value unmodified faces to the same degree as it values modified faces (if not more) because of the former's genuineness. Therefore, opponents seem to misjudge the potential prejudice-enhancing effect of EGD.

Opponents, however, would argue that things are completely different between EGD and plastic surgery. Plastic surgery only modifies facial characteristics; hence, its prejudice-enhancing effect is 
quite constrained. In contrast, ideal EGD can modify almost all human traits (e.g., appearance, IQ, and moral capacity); therefore, it has the potential to enhance prejudice with respect to all these traits. Based on this, it is quite misleading for advocates to put plastic surgery and EGD on the same level and argue for the permission of the latter based on the permission of the former.

\section{Arguments for EGD and the Counterarguments}

In Section 2, we examined some arguments raised against EGD and how advocates combat these arguments. Now, we take the opposite direction and turn to arguments for EGD and its opponents' corresponding counterarguments.

\subsection{Liberty Argument}

Liberalism is a widespread theory in contemporary ethics. The liberty argument states that "people should be free to choose whatever they value and whatever means they want to reach those ends" [6] (p. 499). In the context of EGD, this means that parents should be free to choose their children's characteristics and the means by which they intend to achieve those characteristics. According to this argument, we are obligated to permit EGD because, otherwise, we are depriving parents of their freedom [5].

Unsurprisingly, this argument has been fiercely attacked by opponents. The counterargument is simple. Deprivation of freedom is permissible in certain situations. For instance, there is nothing wrong about depriving someone of his or her freedom so as to prevent a murder. Therefore, avoiding the deprivation of freedom itself cannot be an argument supporting EGD. In fact, opponents believe it is quite ethically right to deprive parents of their freedom in this case because, otherwise, we are depriving children of their freedom to build their own futures. Murray summarizes this argument as follows: "When parents attempt to shape their children's characteristics to match their own preferences and expectations, such an exercise of free choice on the parents' part may harm their child's prospects for flourishing" [6] (p. 500).

Proponents might not be convinced by the argument above. They observe that many choices made by parents, such as finding specific jobs for their children, may similarly shape and affect their children's prospects in life. But opponents may rejoin that, in the case of EGD, parents choosing a specific characteristic for their children will influence their future children so much that parents' other choices cannot compare with EGD.

\subsection{Well-Being Argument}

The well-being argument asserts that EGD should be permitted because by opting for this procedure, parents are aiming at enhancing their children's well-being, and it is wrong to prevent parents from doing so-just like it is wrong to prevent parents from offering their children a better diet or better education, as parents do so to enhance their children's well-being. As Savulescu argues, parents who choose not to enhance their children are morally wrong [7]. He assumes that there are two types of parents: "Neglectful Parents" and "Lazy Parents". Neglectful Parents may give birth to a child with stunning intellect but provide him or her with only a simple, readily available, and cheap diets. Because of this, the child's intellect becomes normal. Unlike the Neglectful Parents, the Lazy Parents have a child with normal intellect, but if they provide their child with appropriate dietary supplements, the child's intellect would rise to the same level of the Neglectful Parents' child. Unfortunately, the Lazy Parents do not feed their child such a diet, so the child ends up with a normal intellect. Savulescu thinks that both the Neglectful Parents and the Lazy Parents are morally wrong. Then, Savulescu assumes another scenario: if we substitute the diet with biological intervention (i.e., enhancement), what should parents do? Savulescu's answer is that in order not to harm their children, parents should enhance their children [7] (pp. 521-522).

Opponents immediately frown at this argument. If the "well-being" here refers to avoidance of deadly genetic diseases, opponents would readily agree to permit EGD. Unfortunately, in most cases, 
the "well-being" EGD promises does not concern prevention but enhancement. And with regard to enhancement, there is the timeless conflict between what parents deem as well-being enhancing and what their children consider to be well-being enhancing. So, if the result of EGD does not agree with the children's view of well-being enhancing, parents are in essence forcing an unwanted phenotype onto their children, and this is apparently ethically wrong.

\subsection{Risk Argument}

The risk argument contends that if we totally forbid EGD, it would be driven underground and performed illegally, which would only make the procedure even riskier. In contrast, if we allow EGD, it would be carried out through legal channels and would put us in a better position to monitor and regulate it. Hence, the risk of it would be dramatically decreased. So, we should permit EGD.

This argument is equivalent to the "resistance is futile" argument. It is based on "some notions of historical inevitability: boundaries were shattered in the past, therefore boundaries will fall in the future" [6] (p. 500). That is to say, attempting to restrict enhancements of EGD will be unsuccessful because people will pursue them anyway.

The opponents, though, think otherwise. Take drugs as an example. Following the line of reasoning above, it seems that we ought to allow drug use because, otherwise, we risk driving drug dealing into black markets and hence losing control over it. But this is apparently counterintuitive, because it is absurd to assume that simply legalizing something turns it from being bad to good. That is, if drug use is wrong, instead of simply legalizing it, the right thing is for drugs to only exist on the black market and be otherwise forbidden. The same applies to EGD. If EGD is wrong and prevention of it will drive it underground, the right thing to do is to forbid it and let it simply go underground. Legalizing everything does not help make a better world.

\section{Which Argument is the Core Argument?}

In the sections above, we have provided a general overview of the current discussions of EGD. We see that all the arguments have counterarguments. So, which argument is the most important or core argument? To judge which one is most important, we find that Sandel proposes some arguments for ranking the effectiveness of different arguments, and his ideas can give us some inspiration and serve as the target of our discussion [5]. Actually, Sandel's argument is in line with the future-deciding, commodifying, and against nature arguments, which were discussed in Section 2. That is, Sandel opposes EGD because it represents parents' control, commodifies children, and goes against nature [5]. According to Sandel, arguments concerning safety, injustice, and autonomy cannot ethically defy EGD for the following reasons: Firstly, safety issues over EGD would sooner or later be resolved due to scientific progress. Secondly, any injustice brought by EGD (i.e., children subjected to EGD would possess an unfair edge over those without it) is no bigger than an injustice caused by innate variations among children. Thirdly, although EGD does harm children's autonomy, so does natural pregnancy without EGD, because, in the latter case, children also cannot decide for themselves what kind of phenotype they would exhibit. It has already been decided at the moment of fertilization.

So, if safety, injustice, and autonomy all fail to defy EGD, does it mean it should be permitted? Sandel does not think so. According to Sandel, EGD in nature represents our craving to alter humanity so as to fulfill our desires, and this makes us ungrateful towards humanity, which is given to us as a gift. More specifically, Sandel suggests EGD to be ethically inappropriate based on the idea that children ought to be cherished as gifts and parents should accept them as they originally are instead of adopting EGD to perfect their children. For Sandel, the deep moral problem of EGD concerns "the gifted character of human powers and achievements" and the proper stance of human beings toward the given world [5] (p. 83). He says: "The hyperparenting familiar in our time represents an anxious excess of mastery and dominion that misses the sense of life as gift. This draws it disturbingly close to eugenics" [5] (p. 62). That is to say, EGD is another kind of hyperparenting, and it makes us fail to appreciate our children as the gifts they are. For Sandel, "to appreciate children as gifts is to 
accept them as they come, not as objects of our design, or products of our will, or instruments of our ambition" [5] (p. 45). In fact, according to Sandel, that is why having children teaches parents about being generous towards the unexpected more than any other human activity. Meanwhile, Sandel holds that although the idea of being grateful towards what is given to us in life has a religious root, its ethical power goes far beyond the domain of religion.

\section{A Confucian Solution}

Ruiping Fan, in his Contemporary Confucian Bioethics, compares Sandel's argument with Confucian ideas, and he concludes that, on the one hand, Confucianists agree with Sandel in treating children as gifts [8]. But on the other hand, Confucianists do not subscribe to Sandel's total denial of EGD. To illustrate, let us first think about the following question: Sandel regards children as gifts, but from where do these gifts come? Or, who gives these gifts to parents? Of course, a religious person would say that they are given by God, but that seems not to be what Sandel has in mind, because Sandel suggests that it does not necessarily take religious belief to be able to treat children as gifts. Instead, Sandel asserts that when we say children are gifts, we might mean they come from nature, luck, or simply any other thing upon which we hardly have any control. Therefore, for Sandel, it does not really matter where children as gifts come from; what really matters is that parents should appreciate them as gifts and stop using EGD to modify them with the ungrateful wish for perfect children.

Towards this, Fan holds a different opinion. He thinks that it is quite important to specify where children as gifts come from because, otherwise, how can we fully appreciate children as gifts? [8] Moreover, Fan suggests we must further specify what kind of gifts children are, in what way they are given to parents, and to what purpose they are given to parents.

To answer these questions, Fan points to Confucianism [8]. Firstly, according to Confucianism, children are gifts from a family's ancestors, and by receiving them, parents simultaneously take up two moral obligations: the upward obligation towards ancestors, especially the children's grandparents (i.e., extending the family lineage), and the downward obligation towards the children (i.e., raising them to adulthood). Secondly, Confucianism suggests that children as gifts represent the potential to be morally good. That is, when parents receive children as gifts, they are not receiving the fact that these children are already morally good but the potential that these children could become morally good. Thirdly, according to Confucianism, the purpose of ancestors giving children to parents as gifts is to extend the family lineage and maintain the family's prosperity. Therefore, Fan asserts Confucianism could answer many prominent questions unaddressed by Sandel's argument.

However, this does not mean that Confucianists share Sandel's completely negative attitude regarding EGD. On the contrary, Confucianists hold a more liberal attitude. As mentioned earlier, Confucianists deeply value the prosperity and integrity of a family. Therefore, Confucianists would allow EGD if it serves these two ends. For instance, if parents adopt EGD to raise their children's IQ, Confucianism would tend to allow it because, generally speaking, a child with a high IQ is more likely to enhance the family's prosperity. On the other hand, if EGD compromises a family's prosperity or integrity, Confucianists would go against it. For instance, if parents use EGD to change their children's color from yellow to white, Confucianists would not allow it, because the change in skin color deviates the children from their yellow-skinned ancestors, and this is believed to compromise a family's prosperity and integrity. In sum, unlike Sandel's total denial of EGD, Confucianism takes a more context-sensitive attitude. We endorse this context sensitivity, although we do not agree with the Confucianist ethical judgement in every EGD case. The reason is straightforward. Context is simply undeniable in every situation where we want to make an ethical decision towards certain biological technologies, and we believe EGD is not an exception. The totally context-independent denial of EGD advanced by Sandel would surely avoid the potential dark side of EGD, but this would be achieved at the cost of totally occluding its bright side.

In principle, we agree with Fan's interpretation of Confucianism for solving the EGD problem. But we do not agree with some of his specific ideas. For example, he does not allow parents to use 
EGD to change their children's skin or hair color because this may compromise a family's prosperity and integrity. We think that he might misconstrue the Confucian sense of familial prosperity and integrity. Changing children's skin or hair color might not be permitted, but it is not because it harms one's family's integrity and prosperity but because it is not following traditional customs. As we know, customs might change with development. With the development of a society, new customs might emerge. Then, according to the new customs, changing skin or hair color might be permitted. As we can see now in big cities of China, many students change their hair color without being morally accused.

In [9], I (Jianhui Li) and Yaming Li reached the same conclusion as Fan regarding EGD but along a quite different route. We used the Confucian theory of human dignity to show that, in some contexts, EGD should be permitted, but in some other contexts, it should be prohibited. "Fan's familism argument can be coordinated with our dignity argument: if a genetic enhancement increases a child's potential for personal dignity and his family's potential for prosperity, then it may be favored; if an enhancement decreases a child's potential for personal dignity and his family's potential for prosperity, then it should be banned." [9]

\section{Conclusions}

This paper first provided an overview of the current debate on EGD, from which we concluded that neither side has succeeded in rebutting the other, although opponents of EGD exhibit a modest edge. Then, we focused on a specific argument against EGD famously put forward by Sandel and compared it to Confucianism's attitude towards EGD. Based on this comparison, our conclusion is twofold. On the one hand, Confucianism is able to address many questions unanswered by Sandel's argument, such as who gives children to parents as gifts. On the other hand, unlike Sandel's total denial of EGD, Confucianism holds a context-sensitive attitude towards EGD. That is, Confucianism would allow EGD if it benefits a family's prosperity and integrity. We endorse this context-sensitive Confucianism.

Simply put, as advanced by the International Summit of Human Gene Editing [10], the clinical application of germ-line gene editing is irresponsible unless (1) the risks, benefits, and alternatives have been appropriately discussed and balanced; and (2) a wide social agreement has been achieved regarding the clinical application of that technology. Sadly, the Summit statement asserts that, to date, neither of these two conditions has been satisfied, which is why EGD is forbidden in most countries today. However, the Summit statement also points to the bright side. That is, with the high speed of scientific progress and a corresponding change in public attitude, current policies regarding EGD might change.

Author Contributions: Conceptualization, J.L. and X.Z.; methodology, J.L. and X.Z.; investigation, J.L. and X.Z.; resources, J.L. and X.Z.; writing—original draft preparation for the parts one to three, X.Z.; Parts 4-6, J.L.; writing-review and editing, J.L.; supervision, J.L.; project administration, J.L.; funding acquisition, J.L.

Funding: Supported by the National Social Science Foundation of China (Project code: 14ZDB171)

Conflicts of Interest: The authors declare no conflict of interest. The funders had no role in the design of the study; in the collection, analyses, or interpretation of data; in the writing of the manuscript, or in the decision to publish the results.

\section{Abbreviation}

EGD: embryo gene designing

\section{References}

1. Engelhardt, H.T. The Foundations of Bioethics; Oxford University Press: Oxford, UK, 1986.

2. Beauchamp, T.L.; Childress, J.F. Principles of Biomedical Ethics; Oxford University Press: Oxford, UK, 1979.

3. Steinbock, B. The Oxford Handbook of Bioethics; Oxford University Press: Oxford, UK, 2007.

4. Kass, L. Beyond Therapy: Biotechnology and the Pursuit of Happiness; Harper Perennial: New York, NY, USA, 2003.

5. Sandel, M.J. The Case against Perfection; Harvard University Press: Cambridge, MA, USA, 2009. 
6. Murray, T. Enhancement. In The Oxford Handbook of Bioethics; Steinbock, B., Ed.; Oxford University Press: Oxford, UK, 2007; pp. 516-535.

7. Savulescu, J. Genetic Interventions and the Ethics of Enhancement of Human Beings. In The Oxford Handbook of Bioethics; Steinbock, B., Ed.; Oxford University Press: Oxford, UK, 2007; pp. 516-535.

8. Fan, R. (Ed.) Contemporary Confucian Bioethics; Peking University Press: Beijing, China, 2011.

9. Li, J.; Li, Y. Birth with dignity from the Confucian perspective. Theor. Med. Bioeth. 2018, 39, 375-388. [CrossRef] [PubMed]

10. Baltimore, D.; Baylis, F.; Berg, P.; Daley, G.Q.; Doudna, J.A.; Lander, E.S.; Lovell-Badge, R.; Ossorio, P.; Pei, D.; Thrasher, A.; et al. On Human Gene Editing: International Summit Statement; National Academy of Sciences: Washington, DC, USA, 2015.

(C) 2019 by the authors. Licensee MDPI, Basel, Switzerland. This article is an open access article distributed under the terms and conditions of the Creative Commons Attribution (CC BY) license (http://creativecommons.org/licenses/by/4.0/). 